\title{
Toll-like receptor mediated regulation of breast cancer: a case of mixed blessings
}

\author{
Nabiha Yusuf * \\ Department of Dermatology, University of Alabama at Birmingham, Birmingham, AL, USA \\ ${ }^{*}$ Correspondence: nabiha@uab.edu \\ Edited by: \\ Christophe M. Filippi, Genomics Institute of the Novartis Research Foundation, USA \\ Reviewed by: \\ Masaaki Murakami, Osaka University, Japan
}

Keywords: toll-like receptor, breast cancer, chemotherapy, vaccine, innate immunity

\section{INTRODUCTION}

Breast cancer is the most common type of cancer in American women after skin cancer. It is also the second deadliest cause of fatalities in women, exceeded only by lung cancer (1). There is a lot of variation within the tumors of an individual and also between the tumors of different individuals. These differences account for assessing therapeutic resistance and progression of disease. It is a challenge to characterize these tumors and design effective therapies to control their progression (2). There is a dynamic interaction between the tumors and the immune system, which determines the fate of their existence (3). Most tumors arise as a result of genetic and epigenetic changes that occur within an individual. These changes are often followed by inflammation that helps in the recruitment of inflammatory cells, fibroblasts, and endothelial cells in the microenvironment of host tumor cells. The interaction of tumor cells and the cells of the tumor microenvironment determines the invasive potential of the tumors (4).

\section{INNATE IMMUNE RESPONSES AND CANCER}

The cells of the innate immune system, namely macrophages, dendritic cells (DCs), natural killer (NK), NKT, and $\gamma \delta \mathrm{T}$ cells, play a critical role in hot immune responses against host tumors by various mechanisms (5). Adaptive immune responses play a critical role in elimination of tumor cells by generating more specific tumor immunity and immunological memory (5). Thus, there is a constant interaction between the innate and adaptive arms of the host immune system to generate a strong immune response to detect and eliminate the pathogens and mutated cells before they become tumors (6). Pathogen-associated molecular patterns (PAMPs) are recognition molecules that are associated with groups of pathogens. Damage-associated molecular patterns (DAMPs) are endogenous molecules created upon tissue injury. Both these patterns signal the threat of either infection or injury to the organism and are recognized by a family of innate immune system called the Pattern recognition receptors (PRRs) (7-10). Toll-like receptors (TLRs) are the most well studied among the members of the cellular receptors and are known to play an important role in bridging innate and adaptive immune responses in cancer (6). The innate immune responses generated by TLRs are known to suppress the function of regulatory T-cells (T-regs) by breaking tolerance and enhancing immune responses against cancers $(5,11-13)$. Signaling through TLR activates DCs and macrophages to secrete IL-12, a cytokine that directs the adaptive immune response toward a Th1 phenotype (14). TLRs are not only expressed on immune cells but they are also expressed on cancer cells. The expression of TLRs on the cell type can have different consequences (15). Studies suggest that TLR signaling in tumor cells promote tumor angiogenesis and metastasis. Activation or TLRs by DAMPs released by tissue damage can attract more inflammatory cells to cause chronic inflammation leading to tumor progression (16-18).

\section{TOLL-LIKE RECEPTORS AND IMMUNE SURVEILLANCE IN BREAST CANCER}

Several TLR agonists have been demonstrated to produce anti-tumor effects in breast cancer (11). Some analogs of nucleic acids that activate TLR7 and TLR9 have been used in clinical trials to improve anti-tumor immune response against solid tumors. Additionally, TLR signaling has been shown to decrease or de-repress the effects of regulatory T-cells on DCs or CD8+ T-cells $(19,20)$. Among the tumorinfiltrating lymphocytes, a major population $(70-90 \%)$ of gammadelta $(\gamma \delta)$ cells called $\gamma \delta 1$ T-cells was shown to inhibit naive and effector T-cell responses and block DC maturation and function (21). $\gamma \delta 1$ regulatory T-cells reside naturally in the epithelial tissues and can easily migrate to normal or malignant epithelium. These cells can possibly expand by direct presentation of antigens by tumor cells (21). The immunosuppressive activity of these cells could be reversed by human TLR8 ligands both in vitro and in vivo. These cells required MyD88, TRAF6, IKKalpha IKKbeta, and p38alpha molecules in gammadeltal cells to respond to TLR8 ligands (21). In a model of human HER2/neu(+) breast cancer (neu-transgenic mice), topical treatment with a TLR7 agonist, imiquimod, showed significant regression of spontaneous breast cancers. Analysis of gene expression data from the tumors of these mice revealed that treatment with imiquimod resulted in high levels in addition to TNF-alpha and IFN-gamma. The anti-tumor effect of imiquimod was significantly enhanced by blocking IL10 , thereby increasing survival in these mice. Thus, IL-10 induction maybe a selfregulatory mechanism used by the TLR agonists to control excessive inflammation (22).

Other TLRs expressed on the immune cells have also been reported to improve the efficacy of tumor vaccines or enhancement 
of chemotherapy of breast tumors by enhancing anti-tumor immune responses. When polysaccharide krestin (PSK), a TLR2 agonist was orally consumed in neutransgenic mice, it significantly inhibited breast cancer growth by its action on the CD8 (+) T-cell and NK cells but not CD4 (+) T-cells (23). In another study, another TLR2 agonist polysaccharide A (PSA) was shown to cause inhibition of immune responses by production of IL10 and regulatory T-cells (24). Thus, TLR2 stimulation on immune cells may also have opposing immune effects as in the case of PSA and PSK. Nitrogen bisphosphonates (NBPs) have been shown to cause a rapid influx of neutrophils and monocytes that was dependent via myeloid differentiation primary response gene 88 (MyD88), a downstream adaptor molecule involved in TLR and IL-1 signaling. Using bone marrow chimeras, it was demonstrated that this acute inflammatory response was partially dependent on TLR4 expressed by hematopoietic cells and the IL-1 receptor on radioresistant cells (25). Studies from our laboratory on carcinogenic polyaromatic hydrocarbon 7,12dimethylbenz(a)anthracene (DMBA) have demonstrated that cell mediated immunity to DMBA was dependent on TLR4 and had a protective effect against mammary tumor development. This effect was primarily mediated by IL- 12 secreted by CD11c+ cells in TLR4 proficient mice, which lead to an IFN- $\gamma$ mediated response resulting in fewer tumors (26).

\section{TOLL-LIKE RECEPTORS AND IMMUNOTHERAPY OF BREAST CANCER}

Vaccination strategies using DC/breast carcinoma fusions were effective in generating anti-tumor immune responses patients with metastatic breast cancer, but tumor regression was observed in a minor group of these patients. This was due to the expansion of both activated and regulatory T-cell populations by DC/breast carcinoma fusions, primarily leading to suppression of T-cell responses. TLR9 agonist $\mathrm{CpG}$ oligodeoxynucleotides along with IL-12 and IL-18 was able to reduce the level of fusion-mediated regulatory T-cell expansion. The regulatory T-cell response was inhibited by using TLR agonists that enhanced effector T-cell responses, thus increasing the efficacy of vaccine (27). Effective immunotherapy using combination of HER-2/neu genetic vaccine and novel agonist of TLR9 has been reported for breast cancer. This therapy has been reported to be associated with antibody isotype switch and antibodydependent cellular cytotoxicity activity of the of DNA-EP/Ad-based cancer vaccines (28). Vaccination with Ad-BD2-E1A (E1Bdeleted oncolytic adenovirus expressing beta-defensin-2) vaccine inhibited primary breast tumor growth and blocked metastasis in a TLR4 dependent manner, thus suggesting the critical role of TLR4 in the induction of anti-tumor immunity by Ad-BD2-E1A (29).

\section{TOLL-LIKE RECEPTORS AND CHEMOTHERAPY OF BREAST CANCER}

The efficacy of chemotherapy is defined by their ability to perturb the division of tumor cells. A successful outcome of chemotherapy or radiotherapy also involves inclusion of an adjuvant that would enhance the efficacy of chemoor radiotherapy. One such adjuvant, high mobility group box 1 protein (HMGB1) has been successfully used in therapy of breast cancer. Dying tumor cells release HMGB1 that has been shown to activate TLR4 on DCs. It was shown that TLR4 expressed on DCs was required for the cross presentation of tumor antigens and the promotion of tumor specific cytotoxic T-cell responses. Breast cancer patients harboring the loss-of-function Asp299Gly polymorphism of TLR4 relapsed earlier after receiving anthracycline-based chemotherapy. These data suggests that HMGB1- and TLR4-dependent immune responses elicited by conventional cancer treatment may increase the probability of achieving a lasting therapeutic success (30). When small nucleotide polymorphisms (SNPs) in TLR2, TLR3, TLR4, and TLR9 were assessed for their association with breast cancer, no association was found. However, population genetics data has revealed that a hypomorphic variant of TLR4 (p.Asp299Gly) allele was found with no specific allelic frequency $(8.4 \%)$ in the Croatian population compared to other Caucasians (6.5-10\%) (31). The development of drugs targeting TLRs is an emerging area, and there are about 20 drugs that are in pre-clinical and clinical trials (32).

\section{TOLL-LIKE RECEPTORS AND BREAST CANCER CELLS}

In addition to their expression on immune cells, TLRs are also expressed on tumor cells (15). Activation of TLR expressed on tumor cells may enhance tumor growth by increasing pro-survival signals, anti-apoptotic signals, tumor promoting cytokines, angiogenesis, and invasiveness (33, 34). Among the TLRs (TLR1-10), expressed on human breast cancer cell line MDA-MB-231, expression of TLR4 was found to be the highest, and knockdown of TLR4 gene resulted in significant cell death and inhibition of IL- 6 and IL-8 cytokines, compared with vector control (33). In another study, TLR9 was shown to increase invasion of MDAMB-231 cells, by increasing the activity of matrix metalloproteinase 13 (MMP13) (35). TLR3, TLR4, and TLR9 have been shown to be highly expressed in human breast tumors. There was also an increase in the expression of TLR4 by mononuclear inflammatory cells and TLR9 by fibroblastlike cells in mammary tumors. There was more metastasis in TLR3 expressing tumor cells, TLR4 expressing inflammatory cells but not in TLR9 expressing fibroblasts like cells (36). TLR9 isoforms A and B has been detected in clinical breast cancer, and $\mathrm{ER} \alpha$ and sex steroid hormones have been shown to contribute to its invasiveness. TLR9 expression was also found to be affected by the hormonal cancer therapy using bicalutamide (37). In a randomized clinical trial using poly (A:U) dsRNA, TLR3 agonist, chemotherapy was enhanced in patients with TLR3-positive cancers. Chemotherapy using poly A:U was successful only when it was combined with an immunochemotherapeutic regimen of vaccination against tumor antigens (38). In a recent study, it was found that activation of TLR 5 on breast cancer cells by its agonist flagellin, led to inhibition of cell proliferation and anchorage dependent cell growth. This was further confirmed in mouse xenograft models using human breast cancer cells. This inhibitory activity was further confirmed in vivo using mouse xenografts of human 


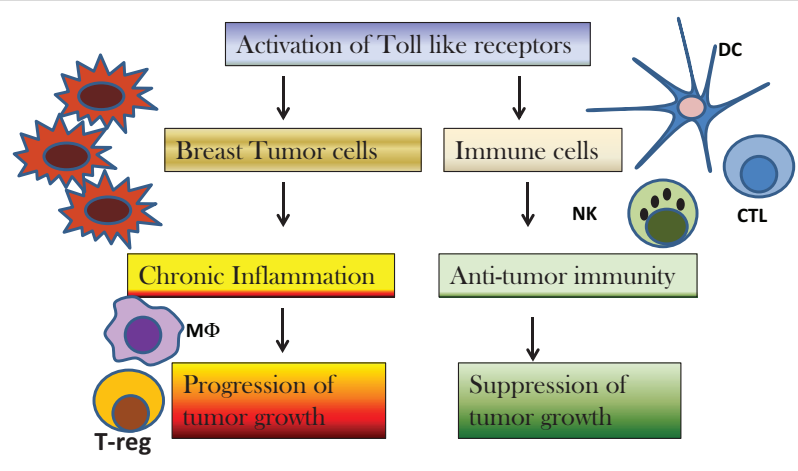

FIGURE 1 | Diagram to depict the effect of activation of toll-like receptors (TLRs) on breast cancer cells versus immune cells. Activation of TLRs on breast cancer cells results in chronic inflammation and recruitment of macrophages $(M \Phi)$ and regulatory T-cells (T-reg) in the tumor microenvironment that cause suppression of immune responses and progression of tumor growth. Activation of TLRs by TLR agonists cause infiltration of dendritic cells (DC), natural killer (NK) cells, and cytotoxic T-cells (CTL) that result in suppression of tumor growth.

breast cancer cells (39). Inflammatory signals generated by TLR signaling have also been reported to increase expression of chemokines, thus causing an influx of Th17 cells by tumor cells and tumor derived fibroblasts (40).

\section{CONCLUSIONS AND PERSPECTIVES}

Discovery of the role of TLRs in cancer biology have paved the way for development of new therapies targeting TLRs. There is a lot of interest to study the relation between inflammation and cancer as it has been termed as the seventh hallmark of cancer. TLRs play an important role in inflammation mediated cancers as well as cancer related inflammation. Activation of TLRs for therapy may be an exciting proposition, but one has to be careful as over activation of TLRs can also lead to development of tumors (Figure 1). Thus, regulatory mechanisms should also be taken into account before using TLRs for cancer therapy. Furthermore, molecular and genetic analysis of breast cancer subtypes should be considered before deciding the course of therapy with TLRs. There are some reports on the role of genetic polymorphisms in TLRs in the outcome of breast cancer therapy. More studies need to be conducted to determine whether the loss or gain of function polymorphisms in TLRs is an indicator of disease outcome or therapy.

\section{REFERENCES}

1. American Cancer Society. Breast Cancer Facts and Figures 2013-2014. Atlanta, GA: American Cancer Society (2013).
2. Polvak K. Heterogeneity in breast cancer. J Clin Invest (2011) 12:3786-8. doi:10.1172/JCI60534

3. Yu H, Kortylewski M, Pardoll D. Crosstalk between cancer and immune cells: role of STAT3 in the tumor microenvironment. Nat Rev Immunol (2007) 7:41-51. doi:10.1038/nri1995

4. Hanahan D, Weinberg RA. The hallmarks of cancer. Cell (2000) 100:57-70. doi:10.1016/S00928674(00)81683-9

5. Dunn GP, Old LJ, Schreiber RD. The immunobiology of cancer immunosurveillance and immunoediting. Immunity (2004) 21:137-48. doi:10. 1016/j.immuni.2004.07.017

6. Matzinger P. Tolerance, danger, and the extended family. Annu Rev Immunol (1994) 12:991-1045. doi:10.1146/annurev.immunol.12.1.991

7. Beutler B. Neo-ligands for innate immune receptors and the etiology of sterile inflammatory disease. Immunol Rev (2007) 220:113-28. doi:10. 1111/j.1600-065X.2007.00577.x

8. Bianchi ME. DAMPs, PAMPs and alarmins: all we need to know about danger. J Leukoc Biol (2007) 81:1-5. doi:10.1189/jlb.0306164

9. Gordon S. Pattern recognition receptors: doubling up for the innate immune response. Cell (2002) 111:927-30. doi:10.1016/S0092-8674(02) 01201-1

10. Medzhitov R, Janeway CA Jr. Decoding the patterns of self and nonself by the innate immune system. Science (2002) 296:298-300. doi:10.1126/science. 1068883

11. Huang B, Zhao J, Unkeless JC, Feng ZH, Xiong H. TLR signaling by tumor and immune cells: a double edged sword. Oncogene (2008) 27:218-24. doi:10.1038/sj.onc.1210904

12. Creagh EM, O'Neill LA. TLRs, NLRs and RLRs: a trinity of pathogen sensors that co-operate in innate immunity. Trends Immunol (2006) 27:352-7. doi:10.1016/j.it.2006.06.003

13. Wang RF, Miyahara Y, Wang HY. Toll-like receptors and immune regulation: implications for cancer therapy. Oncogene (2008) 27:181-9. doi:10.1038/ si.onc. 1210906

14. Akira S, Uematsu S, Takeuchi O. Pathogen recognition and innate immunity. Cell (2006) 124:783-801. doi:10.1016/j.cell.2006.02.015
15. Iwasaki A, Medzhitov R. Toll-like receptor control of the adaptive immune responses. Nat Immunol (2004) 5:987-95. doi:10.1038/nil112

16. Huang B, Zhao J, Li H, He KL, Chen Y, Chen $\mathrm{SH}$, et al. Toll-like receptors on tumor cells facilitate evasion of immune surveillance. Cancer Res (2005) 65:5009-14. doi:10.1158/0008-5472. CAN-05-0784

17. Huang B, Zhao J, Shen S, Li H, He KL, Shen $\mathrm{GX}$, et al. Listeria monocytogenes promotes tumor growth via tumor cell toll-like receptor 2 signaling. Cancer Res (2007) 67:4346-52. doi:10.1158/00085472.CAN-06-4067

18. Kelly MG, Alvero AB, Chen R, Silasi DA, Abrahams VM, Chan S, et al. TLR-4 signaling promotes tumor growth and paclitaxel chemoresistance in ovarian cancer. Cancer Res (2006) 66:3859-68. doi:10.1158/0008-5472.CAN-05-3948

19. Pasare C, Medzhitov R. Toll pathway-dependent blockade of CD4+CD25+ T cell-mediated suppression by dendritic cells. Science (2003) 299:1033-6. doi:10.1126/science.1078231

20. Yang Y, Huang CT, Huang X, Pardoll DM. Persistent Toll-like receptor signals are required for reversal of regulatory T cell-mediated CD8 tolerance. Nat Immunol (2004) 5:508-15. doi:10.1038/ ni1059

21. Peng G, Wang HY, Peng W, Kiniwa Y, Seo KH, Wang RF. Tumor-infiltrating gammadelta $\mathrm{T}$ cells suppress $\mathrm{T}$ and dendritic cell function via mechanisms controlled by a unique toll-like receptor signaling pathway. Immunity (2007) 27:334-48. doi:10.1016/j.immuni.2007.05.020

22. Lu H, Wagner WM, Gad E, Yang Y, Duan $H$, Amon LM, et al. Treatment failure of a TLR-7 agonist occurs due to self-regulation of acute inflammation and can be overcome by IL-10 blockade. J Immunol (2010) 184:5360-7. doi:10.4049/ jimmunol.0902997

23. Lu H, Yang Y, Gad E, Wenner CA, Chang A, Larson ER, et al. Polysaccharide krestin is a novel TLR2 agonist that mediates inhibition of tumor growth via stimulation of CD8 T cells and NK cells. Clin Cancer Res (2011) 17:67-76. doi:10.1158/10780432.CCR-10-1763

24. Round JL, Mazmanian SK. Inducible Foxp3+ regulatory T-cell development by a commensal bacterium of the intestinal microbiota. Proc Natl Acad Sci U S A (2010) 107:12204-9. doi:10.1073/pnas. 0909122107

25. Norton JT, Hayashi T, Crain B, Corr M, Carson DA. Role of IL-1 receptor-associated kinase$\mathrm{M}$ (IRAK-M) in priming of immune and inflammatory responses by nitrogen bisphosphonates. Proc Natl Acad Sci U S A (2011) 108:11163-8. doi:10.1073/pnas.1107899108

26. Naseemuddin M, Iqbal A, Nasti TH, Ghandhi JL, Kapadia AD, Yusuf N. Cell mediated immune responses through TLR4 prevents DMBA-induced mammary carcinogenesis in mice. Int J Cancer (2011) 130:765-74. doi:10.1002/ijc. 26100

27. Vasir B, Wu Z, Crawford K, Rosenblatt J, Zarwan C, Bissonnette A, et al. Fusions of dendritic cells with breast carcinoma stimulate the expansion of regulatory $\mathrm{T}$ cells while concomitant exposure to IL-12, CpG oligodeoxynucleotides, and anti-CD3/CD28 promotes the expansion of activated tumor reactive cells. J Immunol 
(2008) 181:808-21. doi:10.4049/jimmunol.181.1. 808

28. Aurisicchio L, Peruzzi D, Conforti A, Dharmapuri S, Biondo A, Giampaoli S, et al. Treatment of mammary carcinomas in HER-2 transgenic mice through combination of genetic vaccine and an agonist of Toll-like receptor 9. Clin Cancer Res (2009) 15:1575-84. doi:10.1158/1078-0432.CCR08-2628

29. Lapteva N, Aldrich M, Rollins L, Ren W, Goltsova $\mathrm{T}$, Chen SY, et al. Attraction and activation of dendritic cells at the site of tumor elicits potent antitumor immunity. Mol Ther (2009) 17:1626-36. doi:10.1038/mt.2009.111

30. Apetoh L, Ghiringhelli F, Tesniere A, Obeid M, Ortiz C, Criollo A, et al. Toll-like receptor 4 -dependent contribution of the immune system to anticancer chemotherapy and radiotherapy. Nat Med (2007) 13:1050-9. doi:10.1038/ nm1622

31. Etokebe GE, Knezevic J, Petricevic B, Pavelic J, Vrbanec D, Dembic Z. Single-nucleotide polymorphisms in genes encoding toll-like receptor $-2,-3$, -4 , and -9 in case-control study with breast cancer. Genet Test Mol Biomarkers (2009) 13:729-34. doi:10.1089/gtmb.2009.0045

32. Hennessy EJ, Parker AE, O'Neill LA. Targeting Toll-like receptors: emerging therapeutics? Nat Rev Drug Discov (2010) 9:293-307. doi:10.1038/ $\operatorname{nrd} 3203$

33. Allavena P, Sica A, Garlanda C, Mantovani A. The Yin-Yang of tumor-associated macrophages in neoplastic progression and immune surveillance. Immunol Rev (2008) 222:155-61. doi:10.1111/j. 1600-065X.2008.00607.x

34. Yang H, Zhou H, Feng P, Zhou X, Wen H, Xie $\mathrm{X}$, et al. Reduced expression of Toll-like receptor 4 inhibits human breast cancer cells proliferation and inflammatory cytokines secretion. J Exp Clin Cancer Res (2010) 29:92. doi:10.1186/1756-996629-92

35. Merrell MA, Ilvesaro JM, Lehtonen N, Sorsa T, Gehrs B, Rosenthal E, et al. Toll-like receptor 9 agonists promote cellular invasion by increasing matrix metalloproteinase activity. $\mathrm{Mol} \mathrm{Can-}$ cer Res (2006) 4:437-47. doi:10.1158/1541-7786. MCR-06-0007

36. González-Reyes S, Marín L, González L, González LO, del Casar JM, Lamelas ML, et al. Study of TLR3, TLR4 and TLR9 in breast carcinomas and their association with metastasis. BMC Cancer (2010) 10:665. doi:10.1186/1471-2407-10-665

37. Sandholm J, Kauppila JH, Pressey C, Tuomela J, Jukkola-Vuorinen A, Vaarala M, et al. Estrogen receptor- $\alpha$ and sex steroid hormones regulate Tolllike receptor-9 expression and invasive function in human breast cancer cells. Breast Cancer Res Treat (2012) 132:411-9. doi:10.1007/s10549-0111590-3

38. Salaun B, Zitvogel L, Asselin-Paturel C, Morel Y, Chemin K, Dubois C, et al. TLR3 as a biomarker for the therapeutic efficacy of double-stranded RNA in breast cancer. Cancer Res (2011) 71:1607-14. doi:10.1158/0008-5472.CAN-10-3490
39. Cai Z, Sanchez A, Shi Z, Zhang T, Liu M, Zhang D. Activation of Toll-like receptor 5 on breast cancer cells by flagellin suppresses cell proliferation and tumor growth. Cancer Res (2011) 71:2466-75. doi:10.1158/0008-5472.CAN-10-1993

40. Su X, Ye J, Hsueh EC, Zhang Y, Hoft DF, Peng G. Tumor microenvironments direct the recruitment and expansion of human Th17 cells. J Immunol (2010) 184:1630-41. doi:10.4049/ jimmunol.0902813

Conflict of Interest Statement: The author declares that the research was conducted in the absence of any commercial or financial relationships that could be construed as a potential conflict of interest.

Received: 24 December 2013; accepted: 01 May 2014; published online: 16 May 2014.

Citation: Yusuf N (2014) Toll-like receptor mediated regulation of breast cancer: a case of mixed blessings. Front. Immunol. 5:224. doi: 10.3389/fimmu.2014.00224

This article was submitted to Immunological Tolerance, a section of the journal Frontiers in Immunology. Copyright $\odot 2014$ Yusuf. This is an open-access article distributed under the terms of the Creative Commons Attribution License (CC BY). The use, distribution or reproduction in other forums is permitted, provided the original author(s) or licensor are credited and that the original publication in this journal is cited, in accordance with accepted academic practice. No use, distribution or reproduction is permitted which does not comply with these terms. 